\title{
Biosynthetic of Titanium Dioxide Nanoparticles Using Zizyphus Spina-Christi Leaves Extract: Properties
}

\author{
Tuqa B. Alobaidi', Abeer I. Alwared ${ }^{1 *}$ \\ 1 Department of Environmental Engineering, University of Baghdad, Baghdad, Iraq \\ * Corresponding author's e-mail: dr.abeer.wared@coeng.uobaghdad.edu.iq
}

\begin{abstract}
The present project utilizes a straightforward, inexpensive, and environmentally friendly approach to produce Titanium dioxide nanoparticles utilizing Zizyphus Spina-Christi leaves $\left(\mathrm{Z}-\mathrm{TiO}_{2}\right)$. Ultra-Spectrophotometry (UV-Vis) was used to characterize the synthesized nanoparticles, which showed the production of nanoparticles at $320 \mathrm{~nm}$ absorbance. To investigate functional groups, Fourier Transform Infrared Spectroscopy (FTIR) has been used. The presence of Titanium Dioxide was verified using Energy Distribution X-ray Spectroscopy (EDS). Surface area is calculated using the Brunauer Emmett Teller (BET) formula. Images from Field Emission Electron Microscopy (FE-SEM) verified the nanoparticles' spherical shape and relatively homogenous size distribution. These findings demonstrated that the production of $\mathrm{Z}-\mathrm{TiO}_{2}$ nanoparticles was successful.
\end{abstract}

Keywords: green synthesis, $\mathrm{TiO}_{2}$, Zizyphus Spina-Christi, band gap, XRD, FE-SEM.

\section{INTRODUCTION}

Global climate change and population growth have put pressure on water supplies. New measures are needed to minimize the growing challenges to water sustainability. Reuse/recovery of treated wastewater generates a new resource while protecting current water supplies. Urban wastewater is a combination of household wastewater, industrial wastewater, and/or rainwater (Shevah, 2019). Urban wastewater is typically treated and released into receiving ecosystems. However, wastewater should be treated using advanced treatment techniques to remove micropollutants that represent a risk in their content. Water treatment plant secondary effluent contains about 200 chemical compounds, many of which are acutely or chronically harmful to aquatic creatures and human and animal health. They are micropollutants that do not disintegrate readily and can have long-term environmental impacts (Richardson, 2019; Carlsen et al., 2013). The advancement of research and technology in the material area has the interest of scientists all over the world. Materials of nanometer sizes have chemical and physical characteristics that are equivalent to bulk materials. This is due to the fact that the smaller the size of the substance, the larger the surface region, therefore the material in the nanoscale order has a very short distance between atoms, allowing for quicker interactions between them. The molecule controlling the size of the sample, modifying the chemical composition, surface modulation, and controlling the interactions between particles can all be used to modify a variety of nanoparticle properties (Hochella et al., 2019). Because nanomaterials have a high adsorption capacity, their operation is simple, they are highly efficient, low-cost, chemically stable, and their presence in adsorption processes makes removal rapid, they are a new field of study (Guan et al., 2020; Ba-Abbad et al., 2012). Nanoparticle materials can be applied widely, such as in the environmental, industrial, and biomedical fields. Nanobiotechnology is the process of creating nanometer-sized particles with specialized functionalities by combining biological principles with physical and chemical techniques (Parveene et al., 2016). The chemical synthesis process involves the chemical reaction of several precursors to produce another nanometer-sized material. The drawbacks 
of physical and chemical methods are the use of toxic solvents, hazardous waste, and high energy consumption (Maurya et al., 2019), As a result, further developments are required to create ecologically safe and renewable nanoparticles.

The biosynthetic process (also known as green synthesis) is a technique for creating nanoparticles that utilize reducing agents obtained from plants and microorganisms. It offers several advantages, including environmental safety, economic effectiveness, biocompatibility, renewable energy, and non-toxicity. (Jalill et al., 2016). sugars, terpenoids, polyphenols, alkaloids, phenolic acids, and proteins are all compounds that can play a role in the biosynthesis of nanoparticles (Parveene et al., 2016).

Ziziphus Spina-Christi (Sedr) is a subtropical evergreen tree native to eastern Africa, the Middle East, and the Indian subcontinent. Spiny branches and small orange fruits. Sedr trees are found worldwide in warm-temperate and subtropical climates. The leaves have traditionally been utilized in folk medicine as a moisturizer, antibacterial, antidiabetic, anti-inflammatory, hypoglycemic, antifungal, antimicrobial, antihypertensive, neuroprotective, antioxidant, anticancer, and immune system modulator (Bozicevic et al., 2017; Zait et al., 2020). The study aims to investigate the biosynthesis of $\mathrm{TiO}_{2}$ nanoparticles utilizing Ziziphus Spina-Christi plant leaves extract as a reducing agent, as well as its effect on the structure and characteristics of the produced nanoparticles.

\section{MATERIAL AND METHODS}

\section{Materials}

Titanium-isopropoxide(IV) (TTIP Sigma-Aldrich, purity $>97 \%$ ) has been utilized to synthesize
$\mathrm{TiO}_{2}$ nanoparticles. Fresh Z-Spina-Christi leaves were obtained from the Al-Jadriya campus of the College of Engineering in Baghdad, Iraq.

\section{Biosynthetic of Z-TiO}

\section{Preparation and extraction of $\mathrm{Z}-\mathrm{TiO}_{2}$}

Fresh Z-Spina-Christi leaves were properly washed with tap water, followed by distilled water, then boiled 50 grams of the leaves for 2 hours at $60{ }^{\circ} \mathrm{C}$ in $125 \mathrm{~mL}$ of distilled water. The extract solution was then filtered with filter paper.

\section{Synthesis of Z-TiO ${ }_{2}$ nanoparticles}

While the extracted solution was being stirred constantly, $10 \mathrm{~mL}$ of Titanium Isopropoxide (TTIP) was added to $250 \mathrm{ml}$ of the extracted solution. For 4 hours, the entire mixture was stirred until white deposition formed at the bottom of the flask. After a night of standing and cooling to room temperature in a laboratory environment, the solution was filtered and dried in a Hot air oven at $80{ }^{\circ} \mathrm{C}$ for 12 hours. The nanoparticles were then calcined in a Muffle furnace for 2 hours at $500{ }^{\circ} \mathrm{C}$.

\section{Characterization of $\mathrm{TiO}_{2}$ and $\mathrm{Z}-\mathrm{TiO}_{2}$}

An Ultra-Spectrophotometry (UV-Vis) has been used to investigate the optical absorption of the nanoparticles sample (UV-1800, SHIMADZU, Japan). A range of wavelengths of 200 to $600 \mathrm{~nm}$ within the spectrum. According to Tauc's figure, the bandgap energy (Eg) was found. Spectra from Fourier-transform infrared (FTIR) have been used to identify the functional groups present on the surface of the $\mathrm{TiO}_{2}$ samples. the FTIR spectrometer

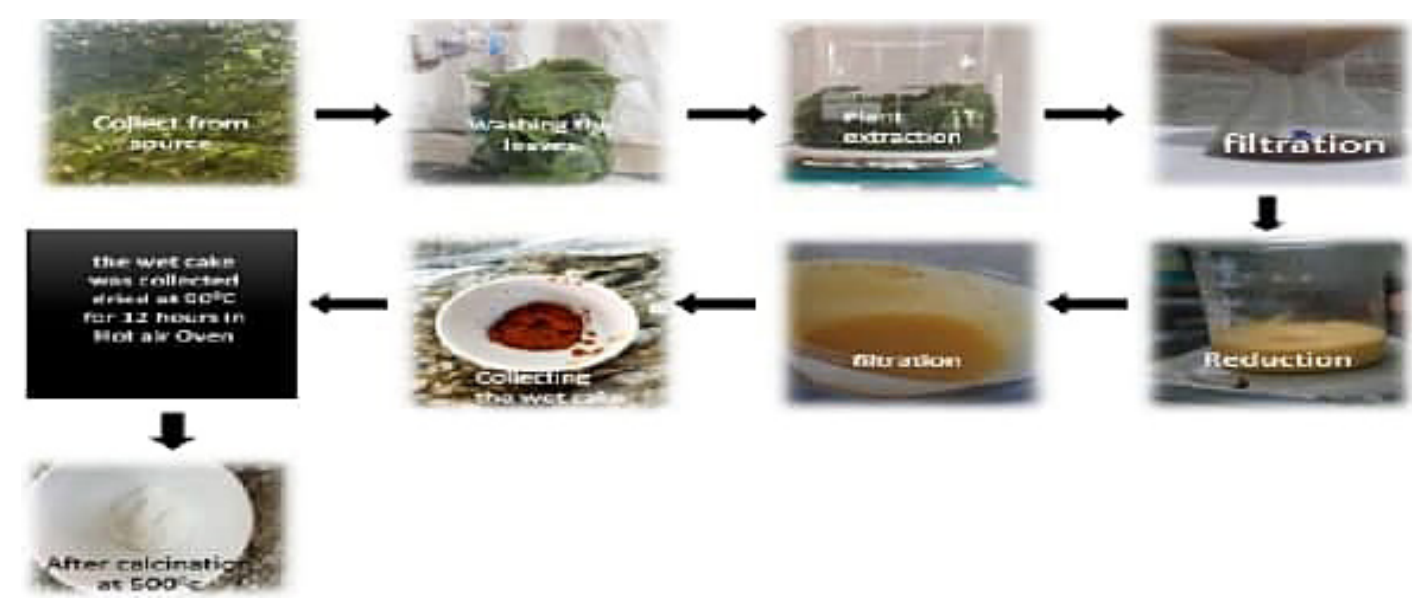

Figure 1. Preparation process of $\mathrm{Z}-\mathrm{TiO}_{2}$ nanoparticles using biosynthesis method 
obtained the spectra in the region of 4000-500 $\mathrm{cm}^{-1}$ (FT-NIR Spectrometer L1390022, PerkinElmer, USA). To have a better understanding of the nanoparticles sample's topography, examined it thru the Field Emission Scanning Electron Microscope image (FESEM TESCAN MIRA3, FRENCH). X-ray diffraction (XRD) method was utilized using a Philips XPERT X'Pert HighScore Plus program to ascertain the structural features, crystallite size, and interplanar distance between crystallographic planes of nanoparticles. The diffraction peaks were recorded in the $10^{\circ}-80^{\circ} 2 \theta$ range (XRD PHILIPS XPERT, HOLLAND). The operation has been performed at a voltage of 10 $\mathrm{kV}$. From the Brunauer-Emmett-Teller (BET) and Barrett-Joyner-Halenda (BJH) analyses, we obtained quantitative information on the surface area and porosity of the sample (MicroActive for TriStar II Plus 2.03, USA).

\section{RESULTS AND DISCUSSION}

\section{Optical properties UV-Vis spectroscopy}

$\mathrm{TiO}_{2}$ exists in three crystal structures: rutile, anatase, and brookite. Photocatalytic investigations have typically focused on rutile and anatase phases (Hamdan at al., 2020). Rutile is the $\mathrm{TiO}_{2}$ phase with the most thermodynamically stable crystal structure while anatase is metastable. (Gao et al., 2019). brookite, on the other hand, is extremely uncommon and unstable. Although the rutile phase has a smaller bandgap $(3.0 \mathrm{eV})$ than the anatase phase $(3.2 \mathrm{eV})$, this phase has higher photocatalytic activity due to the lower electron-hole recombination rate in the anatase crystal structure (De Lasa et al, 2005; Yu, Jiaguo, et al., 2007). Anatase and rutile, on the other hand, have been found in certain investigations (Jing et al., 2008; Francisco et al., 2002; Zhao et al., 2008). There is some disagreement regarding whether the anatase structure has a larger photon absorption capacity and as such higher activity because of the direct or indirect nature of the bandgap. Anatase possesses a metastable crystal structure, although it only exists in tiny crystal sizes. Conversion from anatase to rutile phase is found when crystal size increases (Wang, 2007; Dogu and Karakas, 2018). The characteristics that substantially impact the bandgap of the anatase and rutile phases include the synthesis conditions of these catalysts, the structure of the precursor utilized, the oxygen vacancy number, impurities, crystal size, and type of electronic transition (Reddy et al., 2003; Oliva et al., 2002; Hidalgo et al., 2007; Valencia et al., 2009; Hanaor \& Sorrell, 2011). Figure 2 shows the UV analysis results for $\mathrm{TiO}_{2}$ and $\mathrm{Z}-\mathrm{TiO}_{2}$, the results revealed that maximum absorbance rate was obtained at a wavelength less than $400 \mathrm{~nm}$, In other words, at these wavelengths, $\mathrm{TiO}_{2}$ is impenetrable. This finding is due to the $\mathrm{TiO}_{2}$ nanoparticle's special feature. $\mathrm{TiO}_{2}$ 's specific bandgap absorption causes a substantial increase in absorption at wavelengths less than $400 \mathrm{~nm}$ (Karkare, 2014). Later on, the results of UV-Vis were used for evaluating approximate bandgap energy by using Tauc's relation equation, (Eq. 1), whereas this equation is used for evaluating bandgap at 200-800 nm wavelengths (Kaur et al., 2019). And their results were plotted in Figure 2 also, by extrapolation the linear portion of the plot to the ho axis, the energy of the bandgap was estimated to be (3.276 and 3.204) eV for the commercial and Biosynthetic $\mathrm{TiO}_{2}$, respectively.

$$
(\alpha h v)^{\mathrm{m}}=\beta(\mathrm{h} v-\mathrm{Eg})
$$

where: $\alpha$ represents the extinction coefficient, $\beta$ is the constant and has different values for different transitions, Eg is the energy gap, $\mathrm{h} v$ is the photon energy, m may vary for a different type of band structure.

\section{Fourier Transform Infrared Spectroscopy}

Functional groups of a chemical are determined using Fourier Transform Infrared Spectroscopy (FTIR). At temperatures over zero degrees Kelvin, objects produce infrared radiation. When infrared radiation hits a substance, it is absorbed and causes chemical bonds to vibrate in the substance. (Campanella at al. 2021). The FTIR spectra of the samples (Fig. 3) contain bands in the regions of fundamental natural vibrations $\mathrm{Ti}-\mathrm{O}-$ Ti and $\mathrm{Ti}-\mathrm{O}\left(400-700 \mathrm{~cm}^{-1}\right)$, The bending of C-H and aromatic hydrogen between $1400-1460 \mathrm{~cm}^{-1}$, and $700-900 \mathrm{~cm}^{-1}$ respectively, water vibrations bands in the range of 3600 to $3100 \mathrm{~cm}^{-1}$ there is a peak width corresponding to the vibration of the hydrogen bond with surface $\mathrm{Ti}-\mathrm{OH}$ groups. The characteristic absorption to stress vibration of $\mathrm{C}$ $=\mathrm{O}$ occurs between $1700-1730 \mathrm{~cm}^{-1}$ and another between 1510-1560 $\mathrm{cm}^{-1}$, which corresponds to the carbonyl group (esters). 

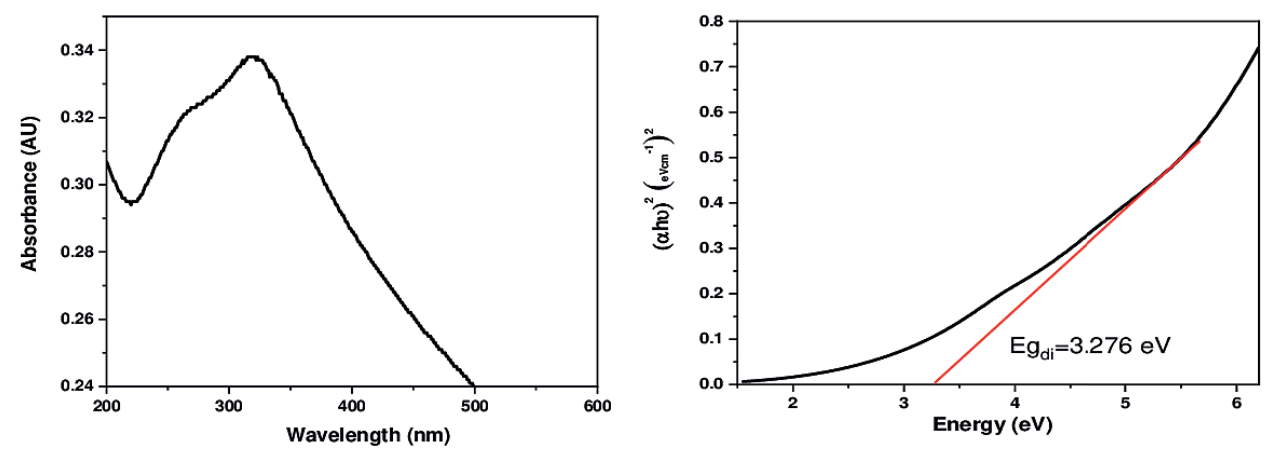

( a) commercial $\mathrm{TiO}_{2}$ nanoparticles
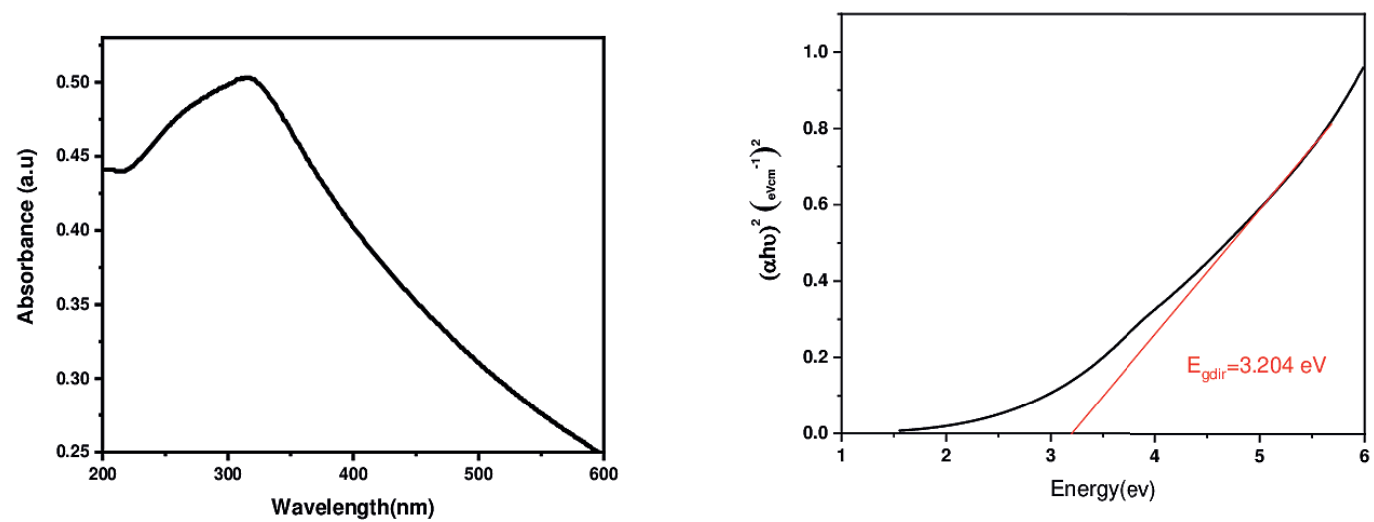

(b) Z-TiO2 nanoparticles

Figure 2. Band gap value of $\mathrm{TiO}_{2}$ and $\mathrm{Z}-\mathrm{TiO}_{2}$ nanoparticles

\section{Field Emission Electron Microscopy}

The microstructure of the $\mathrm{TiO}_{2}$ and $\mathrm{Z}-\mathrm{TiO}_{2}$ was obtained using Field Emission Scanning Electron Microscope (FESEM). As can be seen in (Fig. 4) FESEM at low magnification of $25,000 \mathrm{X}$ with a bar scale of $2 \mu \mathrm{m}$, the $\mathrm{TiO}_{2}$ distribution seems to have more enclosures aggregation. A high surface area is attainable with the configuration of the $\mathrm{TiO}_{2}$ enclosure, which might help in treating wastewater pollution.
The dispersion of nanoparticles on the surface was even when the enclosure's area was covered by a large portion area at a magnification of 200,000 X with a bar size of $200 \mathrm{~nm}$. A creation of $\mathrm{H}^{+}$ions may occur due to the presence of excess $\mathrm{H}_{2} \mathrm{O}$ molecules. Van der Waals forces between $\mathrm{TiO}_{2}-\mathrm{TiO}_{2}$ molecules are lowered through these ions. The results also reveal that the size of $\mathrm{TiO}_{2}$ nanoparticles was below $40 \mathrm{~nm}$ and that the particles have random adherence. The particles have been included in the granular

Table 1. Functional group frequencies of the $\mathrm{TiO}_{2}$ and $\mathrm{Z}-\mathrm{TiO}_{2}$

\begin{tabular}{|c|c|c|c|}
\hline \multicolumn{2}{|c|}{ Wave number $\left(\mathrm{cm}^{-1}\right)$} & \multirow{2}{*}{ Functional groups } & \multirow{2}{*}{ References } \\
\hline $\mathrm{TiO}_{2}$ & $\mathrm{Z}-\mathrm{TiO}_{2}$ & & \\
\hline \multirow[t]{2}{*}{3420.13} & 3195.19 & $-\mathrm{OH}$ & Suwarnkar et al., 2014 \\
\hline & 2918.83 & $\begin{array}{l}\text { hydrogen } \\
\text { bonded alcohols }\end{array}$ & Kaur et al., 2019 \\
\hline \multirow[t]{3}{*}{1630.01} & 1617.26 & titanium carboxilate & García-Serrano et al., 2009 \\
\hline & 1384.62 & bending vibration of carboxylic $\mathrm{O}-\mathrm{H}$ bonds of fatty acids & Kaur et al., 2019 \\
\hline & 1098.19 & Stretching and bending of organic group oxygen frequency & Kaur et al., 2019 \\
\hline $700-400$ & $700-400$ & $\mathrm{Ti}-\mathrm{O}-\mathrm{Ti}$ & Sharaf El-Deen and Zhang, 2016 \\
\hline
\end{tabular}




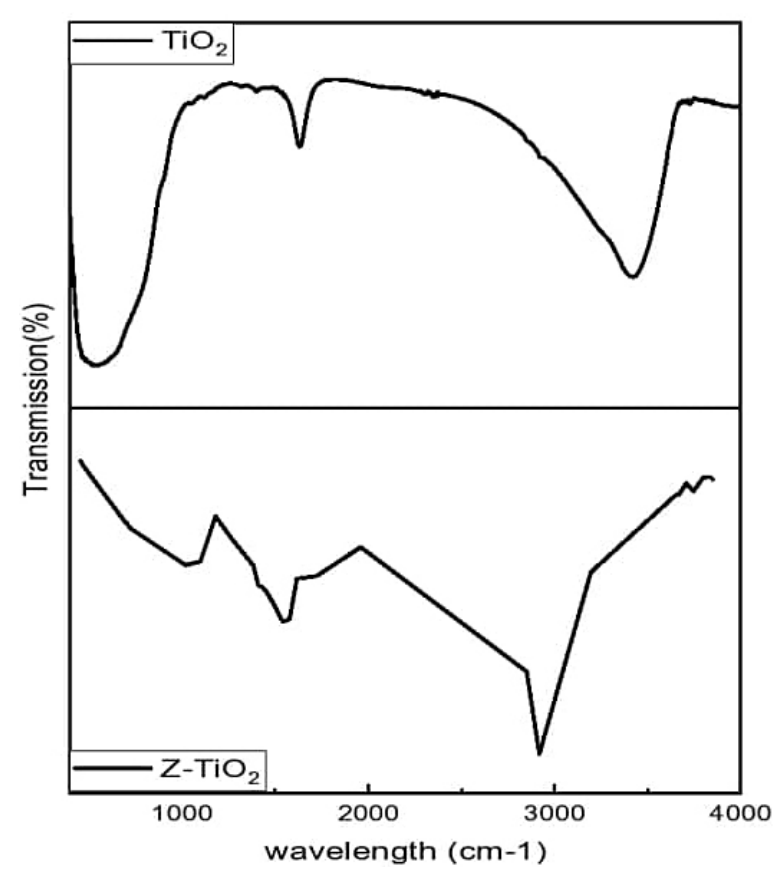

Figure 3. FTIR Spectrum of $\mathrm{TiO}_{2}$ and $\mathrm{Z}-\mathrm{TiO}_{2}$ nanoparticles calcinated

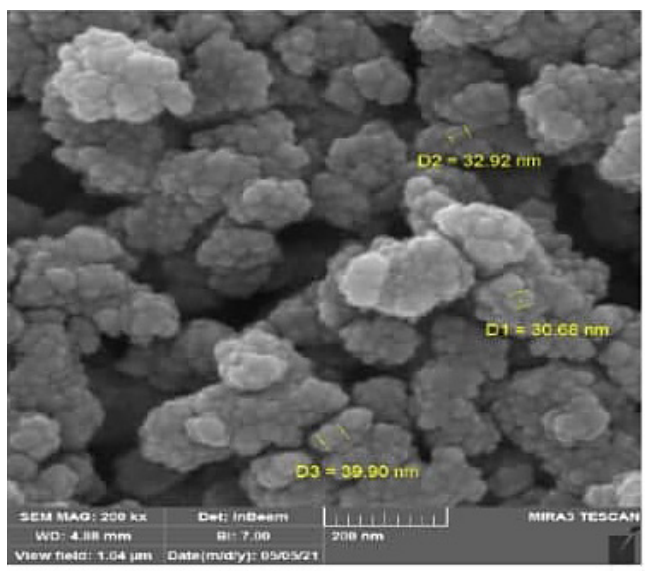

structure. After irradiation with the laser for Z$\mathrm{TiO}_{2}$, all samples show the formation of $\mathrm{TiO}_{2}$ nanoparticles with a spherical shape. Our XRD results are comparable with the observed microstructure. Titanium (Ti), oxygen (O), carbon (C), sulfur (S), and potassium (K) elements and their atomic and weight fractions are shown in the EDX spectrum in Figure 5. The observed peaks of $\mathrm{C}$ and $\mathrm{K}$ are due to the presence of vitamins and minerals $(\mathrm{N}, \mathrm{Na}, \mathrm{Mg}, \mathrm{Ca}, \mathrm{Pd})$ in the $\mathrm{Z}-\mathrm{TiO}_{2}$. This analysis confirms that the high purity of the synthesized $\mathrm{Z}-\mathrm{TiO}_{2}$ indicates the lack of any further impurity elements.

\section{X-Ray characterization}

XRD patterns of the $\mathrm{TiO}_{2}$ and $\mathrm{Z}-\mathrm{TiO}_{2}$ nanoparticles were tested and their results were drawn in Figure 6. The $\mathrm{Z}-\mathrm{TiO}_{2}$ crystallographic structure is determined by XRD high crystallinity is revealed, with strong peaks at $2 \theta$ values

(a) Z-TiO2 Nanoparticles
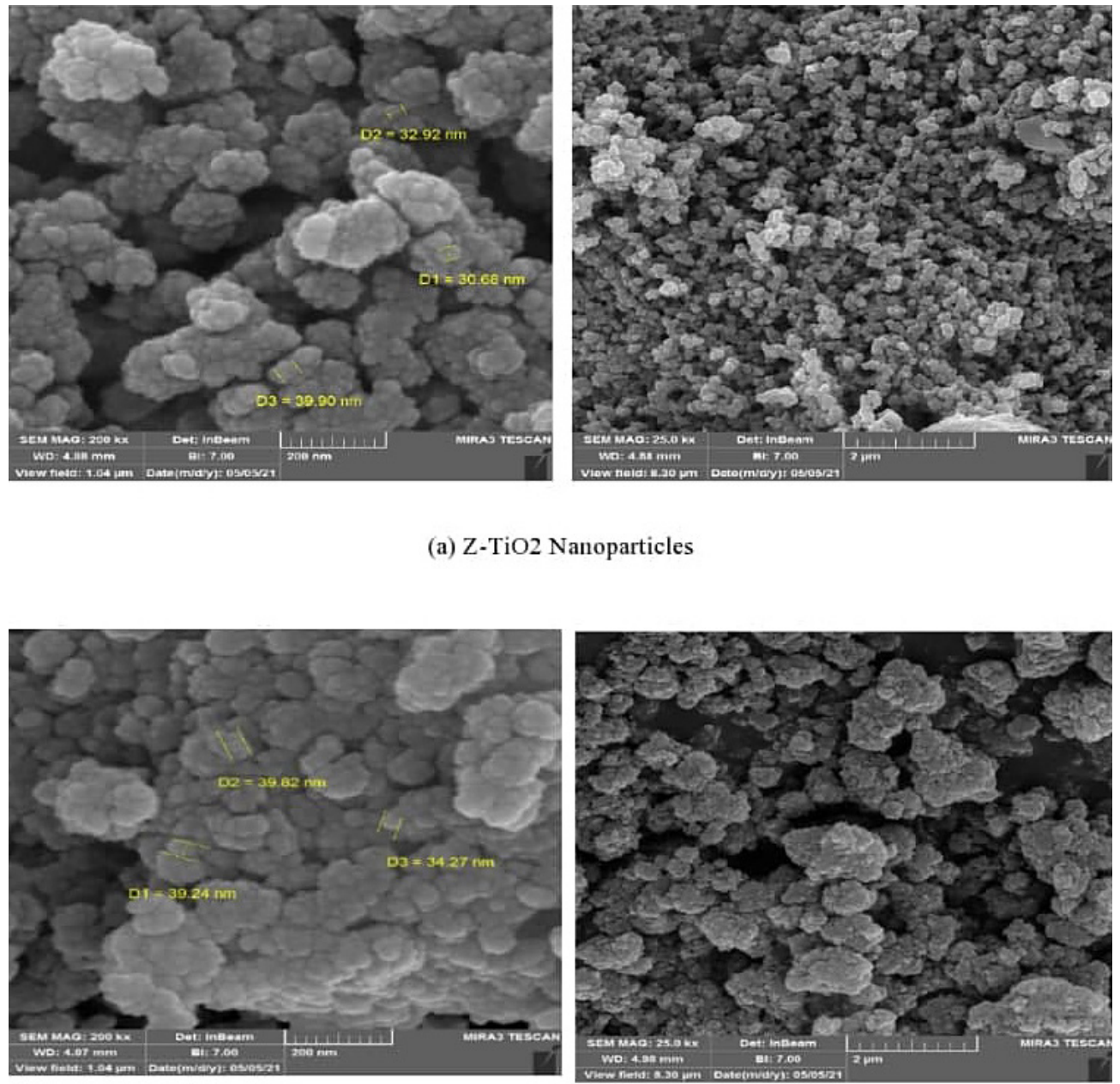

(b) commercial $\mathrm{TiO} 2$ Nanoparticles

Figure 4. FESEM images of $\mathrm{TiO}_{2}$ and $\mathrm{Z}-\mathrm{TiO}_{2}$ 


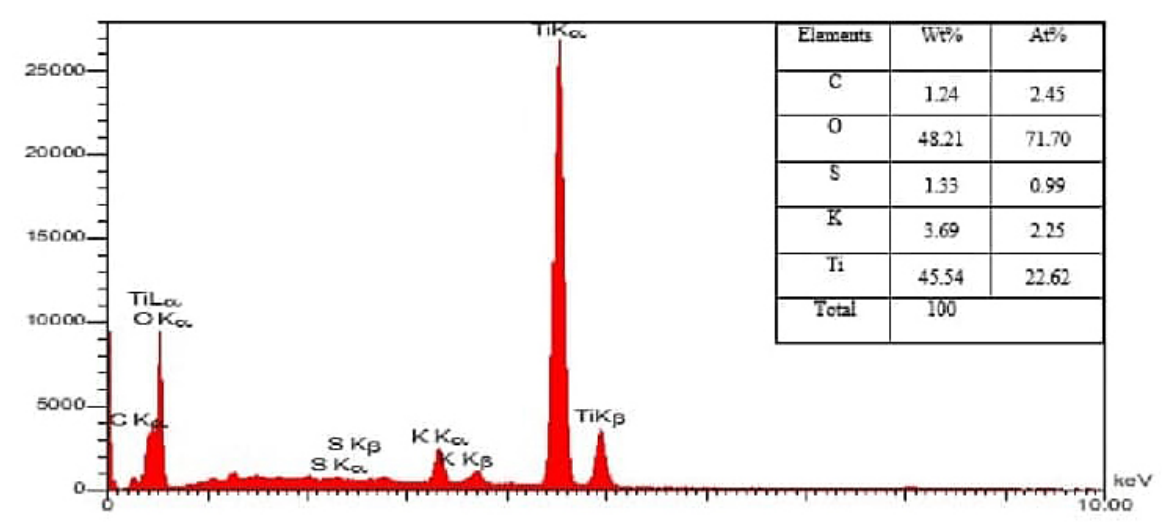

(a) $\mathrm{Z}-\mathrm{TiO}_{2}$ nanoparticles

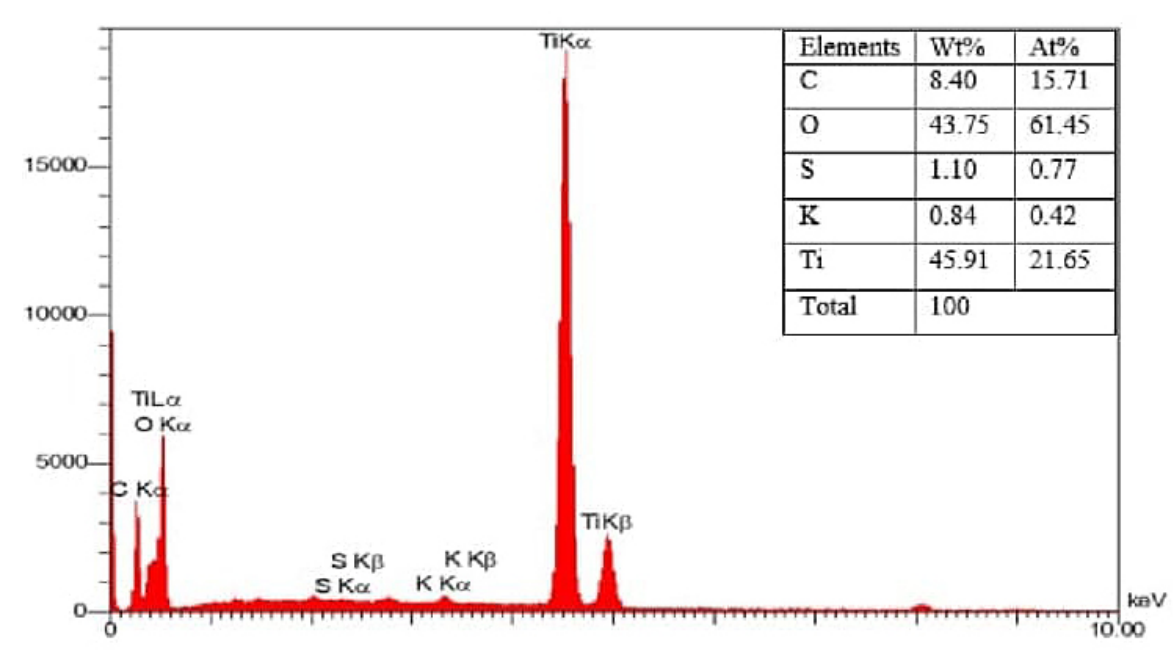

(b) commercial $\mathrm{TiO} 2$ nanoparticles

Figure 5. EDX spectra of $\mathrm{TiO}_{2}$ and $\mathrm{Z}-\mathrm{TiO}_{2}$ nanoparticles and composition of elements

of $25.41,37.95,48.04,54.07,55.07,62.79$, and 69.00 , respectively. which could be indexed to $101,004,200,211,204,220,215$ planes of anatase indicates the production of anatase phase titanium dioxide (Ramalingam, 2019).

The indexed peaks with (h $\mathrm{k} \mathrm{I}$ ) values match the standard card of anatase $\mathrm{TiO}_{2}$ powder sample well (CIF number 96-710-3590). There are no further peaks in the pattern that is related to impurities, indicating that $\mathrm{TiO}_{2}$ is in its pure anatase phase. The diffraction peaks are strong and wide, revealing the crystallinity and nano-sized crystallite composition of the particles, respectively. The broadness of the diffraction peaks is caused by diffraction from a few atoms (crystallite) in the $\mathrm{Z}_{-} \mathrm{TiO}_{2}$, which will be unable to converge into diffraction lines but rather broaden out. Using Debye-equation,
Scherrer's the average crystallite size of $\mathrm{TiO}_{2}$ and $\mathrm{Z}-\mathrm{TiO}_{2}$ was determined from the XRD pattern (Eq. 2) (Mohammadi and Sabourmoghaddam, 2020):

$$
\mathrm{D}=\frac{\mathrm{K} \lambda}{\beta \cos \theta}
$$

where: $\mathrm{D}$ is the size of the crystallite, $\mathrm{K}$ is the Scherrer constant $(K=0.9), \lambda$ is the wavelength of $x$-ray radiation, $\beta$ is the full width at half maximum (FWHM) of the diffraction peak to the corresponding crystallographic plane of anatase, and $\theta$ is the angle of the $\mathrm{x}$-ray diffraction peak.

Table 2 shows the calculated crystallite sizes and calculation of average crystallite size, with 


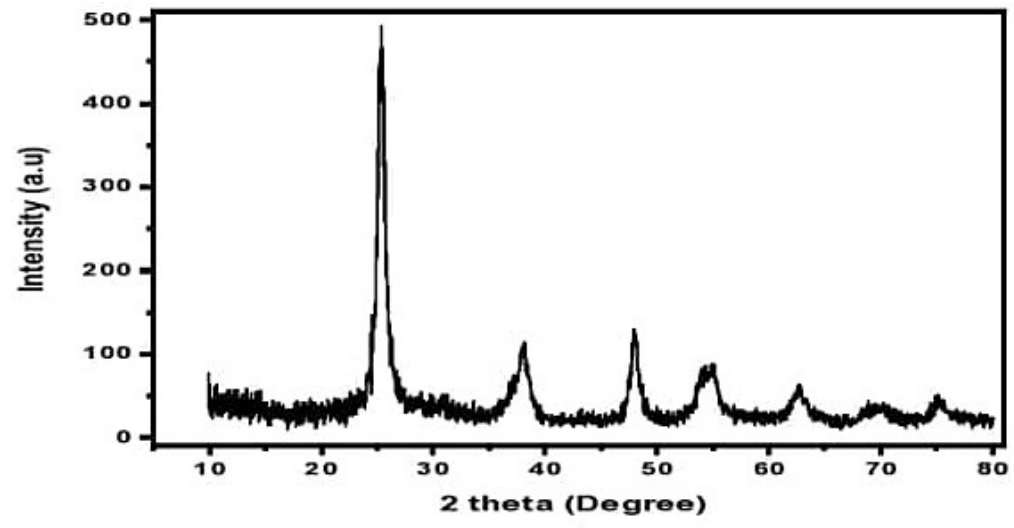

(a) commercial $\mathrm{TiO}_{2}$ Nanoparticles

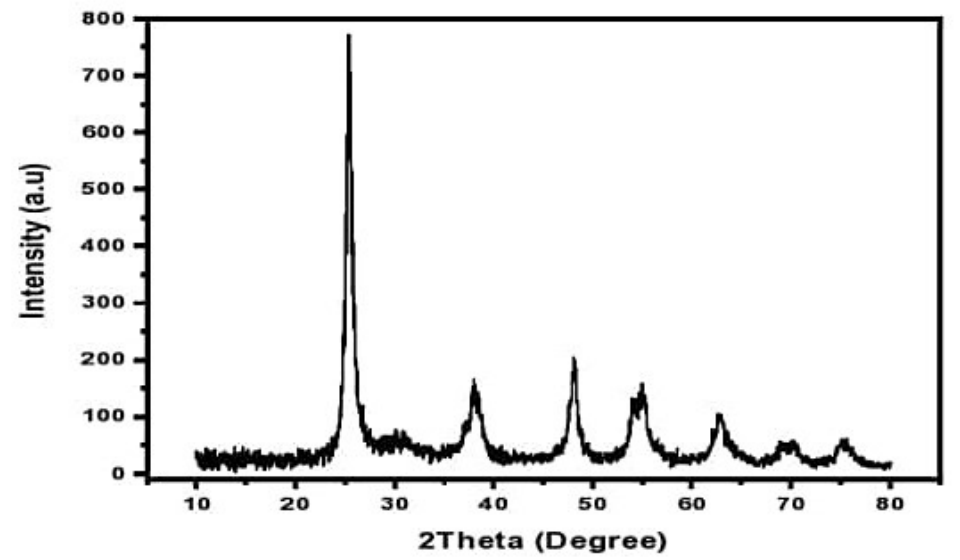

(b) $\mathrm{Z}-\mathrm{TiO}_{2}$.

Figure 6. XRD of nano $\mathrm{TiO}_{2}$ and $\mathrm{Z}-\mathrm{TiO}_{2}$ synthesized

Table 2. $\mathrm{Z}-\mathrm{TiO}_{2}$ and commercial $\mathrm{TiO}_{2}$ structural and geometrical properties

\begin{tabular}{|c|c|c|c|c|c|}
\hline \multicolumn{6}{|c|}{$\mathrm{Z}-\mathrm{TiO}_{2}$} \\
\hline \multirow{2}{*}{ No. } & Peak position & Peak width & Inter-planar distance & Lattice planes & Crystallite size \\
\hline & 2 theta & FWHM(degree) & $\mathrm{d}_{\text {spacing }}(\mathrm{nm})$ & (hkl) & $\mathrm{D}(\mathrm{nm})$ \\
\hline 1 & 25.41754 & 0.2952 & 3.501434901 & 101 & 26.85 \\
\hline 2 & 37.95783 & 0.2952 & 2.368549216 & 004 & 29.72 \\
\hline 3 & 48.04171 & 0.2952 & 1.892307551 & 200 & 30.77 \\
\hline 4 & 54.07883 & 0.3936 & 1.694444235 & 211 & 23.67 \\
\hline 5 & 55.07753 & 0.5904 & 1.666058761 & 204 & 15.85 \\
\hline 6 & 62.792 & 0.492 & 1.478644666 & 220 & 19.76 \\
\hline 7 & 69.00198 & 0.5904 & 1.359943773 & 215 & 17.05 \\
\hline \multicolumn{5}{|l|}{ Average } & 23.38 \\
\hline \multicolumn{6}{|c|}{ Commercial $\mathrm{TiO}_{2}$} \\
\hline \multirow{2}{*}{ No. } & Peak position & Peak width & Inter-planar distance & Lattice planes & Crystallite size \\
\hline & 2 theta & FWHM(degree) & $\mathrm{d}_{\text {spacing }}(\mathrm{nm})$ & (hkl) & $\mathrm{D}(\mathrm{nm})$ \\
\hline 1 & 25.43418 & 0.1968 & 3.50208 & 101 & 43.22 \\
\hline 2 & 38.05194 & 0.492 & 2.36486 & 004 & 17.84 \\
\hline 3 & 48.01968 & 0.492 & 1.89469 & 200 & 18.46 \\
\hline 4 & 53.90468 & 0.7872 & 1.70091 & 211 & 11.82 \\
\hline 5 & 55.10586 & 0.5904 & 1.66665 & 204 & 15.85 \\
\hline 6 & 62.55572 & 0.984 & 1.48489 & 220 & 9.87 \\
\hline \multicolumn{5}{|l|}{ Average } & 19.51 \\
\hline
\end{tabular}


the average crystallite, was $(23.38 \mathrm{~nm})$ for $\mathrm{Z}-\mathrm{TiO}_{2}$ and $(19.51 \mathrm{~nm})$ for $\mathrm{TiO}_{2}$.

\section{Brunauer Emmett Teller}

Nitrogen desorption-adsorption isotherms are prepared by plotting the adsorption capacity calculated from the adsorption-desorption spectra against the relative equilibrium pressure $(\mathrm{P} / \mathrm{Po})$. Where Po indicates the saturated vapor pressure and $\mathrm{P}$ indicates the equilibrium pressure. Brunauer Emmett Teller (BET) analysis can determine the specific surface area $\left(\mathrm{m}^{2} / \mathrm{g}\right)$. The Barrett Joyner and Halden (BJH) technique can be used to determine the specific pore volume $\left(\mathrm{cm}^{3} / \mathrm{g}\right)$, the average pore diameter, and the pore size distribution. (Sutrisno et al., 2018). The pore volume $(\mathrm{V})$, the pore diameter $(\mathrm{D})$, and the pore size distribution were determined by the graph drawn between quantity adsorbed $\left(\mathrm{cm}^{3} / \mathrm{g} \mathrm{STP}\right)$ is given in Figure 7 and in Table 3.

In Figure 7 , the adsorption and desorption isotherms of $\mathrm{Z}-\mathrm{TiO}_{2}$ were obtained at $76.17^{\circ}$ $\mathrm{K}$ liquid nitrogen temperature. Isotherms were prepared by plotting the adsorbed volume data against the relative equilibrium pressure $(\mathrm{P} / \mathrm{Po})$. The bending between 0.2 and $0.9(\mathrm{P} / \mathrm{Po})$ in the adsorbed volume relative equilibrium pressure $(\mathrm{P} / \mathrm{Po})$ graph given in Figure 7 shows the mesoporous size distribution and capillary condensation and the pore size distribution graph of the $\mathrm{Z}-\mathrm{TiO}_{2}$. Materials are classified as microporous, mesoporous, and macroporous according to their pore diameters. Those with a pore diameter of less than $2 \mathrm{~nm}$ are called microporous, those
Table 3. Surface characteristics of the $\mathrm{Z}-\mathrm{TiO}_{2}$

\begin{tabular}{|c|c|c|c|}
\hline Material & $\begin{array}{c}\mathrm{S}_{\text {BET }} \\
\left(\mathrm{m}^{2} / \mathrm{g}\right)\end{array}$ & $\begin{array}{c}\text { Total pore volume } \\
\left(\mathrm{cm}^{3} / \mathrm{g}\right)\end{array}$ & $\begin{array}{c}\text { The pore's average } \\
\text { diameter }(\mathrm{nm})\end{array}$ \\
\hline $\mathrm{Z}-\mathrm{TiO}_{2}$ & 49.2991 & 0.089318 & 8.1908 \\
\hline
\end{tabular}

between 2 and $50 \mathrm{~nm}$ are called mesoporous, and those with a pore diameter of more than 50 $\mathrm{nm}$ are called macroporous or non-porous (Kamegawa et al., 2019). therefore, confirmed that the $\mathrm{TiO}_{2}$ biosynthesized technique has a mesoporous structure with a large surface area and increased pore size, which will stand beneficial for photocatalytic.

\section{CONCLUSION}

A biosynthetic method was used to synthesize titanium dioxide nanoparticles from Zizyphus Spina-Christi leaves extract. This approach has the benefit of not requiring any hazardous solvents or chemicals. UV-Vis spectroscopy, XRD, FTIR, SEM, and BET methods confirmed the formation of $\mathrm{TiO}_{2}$ nanostructures. The structural characteristic of the biosynthesized $\mathrm{TiO}_{2}$ nanoparticles in the XRD and BET study indicates that the average crystallite size of the biosynthetic was $23.38 \mathrm{~nm}$ with the Mesoporous structure. The energy band gap of synthesized $\mathrm{TiO}_{2}$ nanoparticles was determined to be $3.2 \mathrm{eV}$, which is the same as the energy bandgap of commercial $\mathrm{TiO}_{2}$. In the FESEM, the average particle size was determined to be $34.5 \mathrm{~nm}$. The FTIR spectrum revealed $\mathrm{TiO}_{2}$ vibrational bands.
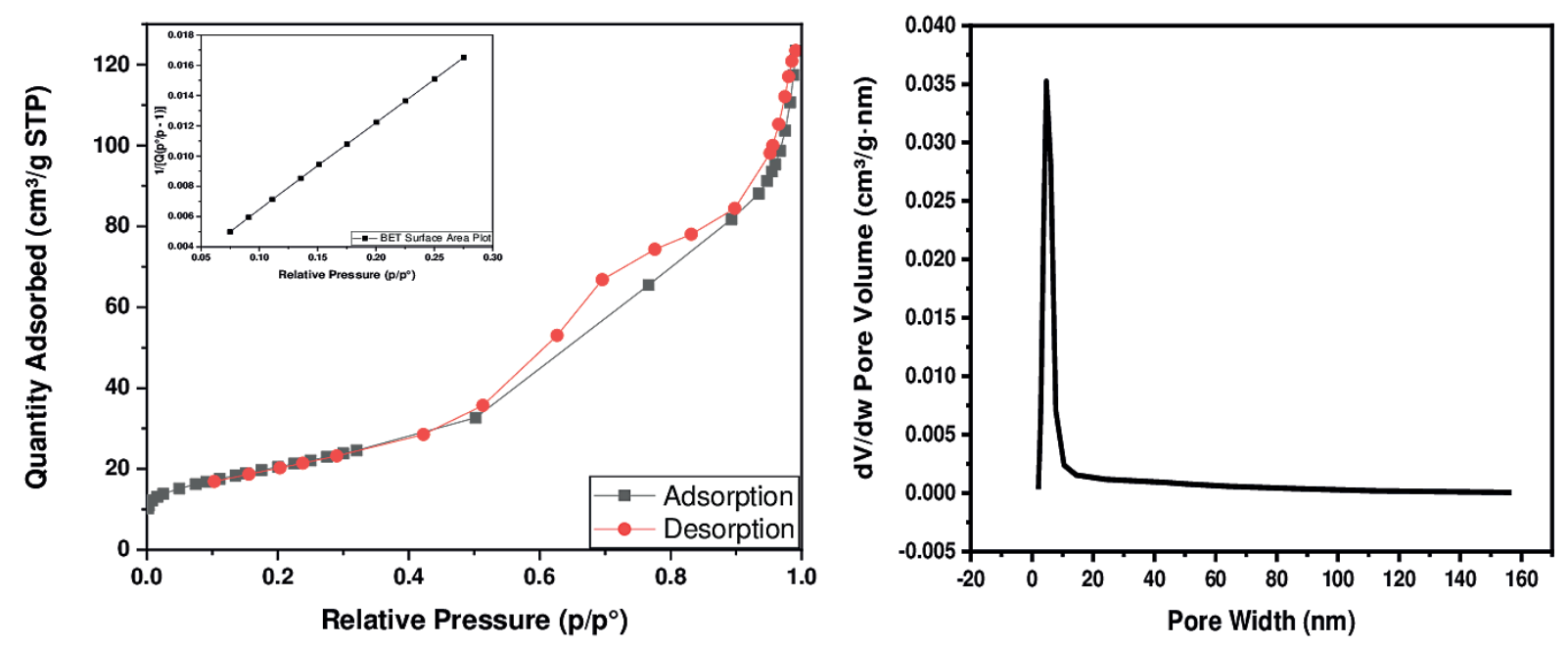

Figure 7. Z- $\mathrm{TiO}_{2}$ nanoparticle's adsorption-desorption isotherms curve 


\section{Acknowledgments}

The authors acknowledge the support received from the University of Baghdad, College of Engineering, Environmental Engineering Department, Iraq.

\section{REFERENCES}

1. Ba-Abbad M.M., Kadhum A.A.H., Mohamad A.B., Takriff M.S., Jalgham R.T. 2012. Comparative study of the adsorption mechanism and photochemical oxidation of chlorophenols on a $\mathrm{TiO} 2$ nanocatalyst. International Journal of Electrochemical Science, 7(11), 11363-11376.

2. Bozicevic A., De Mieri M., Di Benedetto A., Gafner F., Hamburger M. 2017. Dammarane-type saponins from leaves of Ziziphus Spina-Christi. Phytochemistry, 138, 134-144.

3. Campanella B., Palleschi V., Legnaioli S. 2021. Introduction to vibrational spectroscopies. ChemTexts, 7(1), 1-21.

4. Carlsen L., Bruggemann R., Sailaukhanuly Y. 2013. Application of selected partial order tools to analyze fate and toxicity indicators of environmentally hazardous chemicals. Ecological indicators, 29, 191-202.

5. De Lasa H.I., Serrano B., Salaices M. 2005. Photocatalytic reaction engineering. New York: Springer, pp. 193.

6. Dogu D., Karakas G. 2018. Photocatalytic properties and characterization of praseodymium-doped titanium dioxide. Journal of Advanced Oxidation Technologies, 21(1), 215-226.

7. Francisco M.S.P., Mastelaro V.R. 2002. Inhibition of the anatase - rutile phase transformation with addition of $\mathrm{CeO}_{2}$ to $\mathrm{CuO}-\mathrm{TiO}_{2}$ system: Raman spectroscopy, X-ray diffraction, and textural studies. Chemistry of Materials, 14(6), 2514-2518.

8. Gao C., Wei T., Zhang Y., Song X., Huan Y., Liu H., ... and Chen X. 2019. A Photoresponsive Rutile TiO2 Heterojunction with Enhanced Electron-Hole Separation for High-Performance Hydrogen Evolution. Advanced Materials, 31(8), 1806596.

9. García-Serrano J., Gómez-Hernández E., OcampoFernández M., Pal U. 2009. Effect of Ag doping on the crystallization and phase transition of $\mathrm{TiO}_{2}$ nanoparticles. Current Applied Physics, 9(5), 1097-1105.

10. Guan G., Ye E., You M., Li Z. 2020. Hybridized 2D nanomaterials toward highly efficient photocatalysis for degrading pollutants: current status and future perspectives. Small, 16(19), 1907087.

11. Hamdan S.A., IbrahiM I.M., Ali I.M. 2020. Comparison of anatase and rutile $\mathrm{TiO}_{2}$ nanostructure for gas sensing application. Digest Journal of Nanomaterials \& Biostructures (DJNB), 15(4).
12. Hanaor D.A., Sorrell C.C. 2011. Review of the anatase to rutile phase transformation. Journal of Materials science, 46(4), 855-874.

13. Hidalgo M.C., Aguilar M., Maicu M., Navío J.A., Colón G. 2007. Hydrothermal preparation of highly photoactive $\mathrm{TiO}_{2}$ nanoparticles. Catalysis Today, 129(1-2), 50-58.

14. Hochella M.F., Mogk D.W., Ranville J., Allen I.C., Luther G.W., Marr L.C., ... and Yang Y. 2019. Natural, incidental, and engineered nanomaterials and their impacts on the Earth system. Science, 363(6434).

15. Jalill A., Raghad D.H., Nuaman RS, Abd AN. 2016. Biological synthesis of Titanium Dioxide nanoparticles by Curcuma longa plant extract and study its biological properties. World Scientific News, 49(2), 204-222.

16. Jing L., Li S., Song S., Xue L., Fu H. 2008 Investigation on the electron transfer between anatase and rutile in nano-sized $\mathrm{TiO}_{2}$ by means of surface photovoltage technique and its effects on the photocatalytic activity. Solar Energy Materials and Solar Cells, 92(9), 1030-1036.

17. Kamegawa T., Ishiguro Y., Yamashita H. 2019. Photocatalytic properties of $\mathrm{TiO}_{2}$-loaded porous silica with hierarchical macroporous and mesoporous architectures in the degradation of gaseous organic molecules. Catalysis Today, 332, 222-226.

18. Karkare M.M. 2014. Choice of precursor not affecting the size of anatase $\mathrm{TiO}_{2}$ nanoparticles but affecting morphology under broader view. International Nano Letters, 4(3), 111.

19. Kaur H., Goyal V., Singh J., Kumar S., Rawat M. 2019. Biomolecules encapsulated $\mathrm{TiO}_{2}$ nano-cubes using Tinospora cordifolia for photodegradation of a textile dye. Micro \& Nano Letters, 14(12), 1229-1232.

20. Kaur H., Kaur S., Singh J., Rawat M., Kumar S. 2019. Expanding horizon: green synthesis of $\mathrm{TiO}_{2}$ nanoparticles using Carica papaya leaves for photocatalysis application. Materials Research Express, 6(9), 095034.

21. Maurya I.C., Singh S., Senapati S., Srivastava P., Bahadur L. 2019. Green synthesis of TiO nanoparticles using Bixa Orellana seed extract and its application for solar cells. Solar Energy, 194, 952-958.

22. Mohammadi R. and Sabourmoghaddam N. 2020. Adsorption of azo dye methyl orange from aqueous solutions using $\mathrm{TiO}_{2}-\mathrm{SiO}_{2}$ /alginate nanocomposite. Asian Journal of Green Chemistry, 4(1), 107-120.

23. Mohammed, N.A.A., Alwared, A.I., Salman, M.S. 2020. The decolorization of reactive yellow dye by advanced oxidation using continuous reactors. Iraqi Journal of Chemical and Petroleum Engineering, 21(2), 1-6. 
24. Oliva F.Y., Avalle L.B., Santos E., Cámara O.R. 2002. Photoelectrochemical characterization of nanocrystalline $\mathrm{TiO}_{2}$ films on titanium substrates. Journal of photochemistry and photobiology A. Chemistry, 46(3), 175-188.

25. Parveen K., Banse V., Ledwani L. 2016. Green synthesis of nanoparticles: their advantages and disadvantages. In AIP conference proceedings, 1724(1), 020048.

26. Ramalingam S. 2019. Synthesis of Nanosized Titanium Dioxide $\left(\mathrm{TiO}_{2}\right)$ by Sol-Gel Method. Int. J. Innov. Technol. Explore. Eng., 2278-3075.

27. Reddy K.M., Manorama S.V., Reddy A.R. 2003. Bandgap studies on anatase titanium dioxide nanoparticles. Materials Chemistry and Physics, 78(1), 239-245.

28. Richardson S.D., Kimura S.Y. 2019. Water analysis: emerging contaminants and current issues. Analytical Chemistry, 2(1), 473-505.

29. Sharaf El-Deen S.E., Zhang F.S. 2016. Immobilisation of TiO2-nanoparticles on sewage sludge and their adsorption for cadmium removal from aqueous solutions. Journal of experimental nanoscience, 11(4), 239-258.

30. Shevah Y. 2019. Impact of Persistent Droughts on the Quality of the Middle East Water Resources. InSeparation Science and Technology. Academic Press, 11, 51-84.

31. Sutrisno H., Siswani E.D., Budiasih K.S. 2018. The effect of sintering temperatures of $\mathrm{TiO}_{2}$
(B)-nanotubes on its microstructure. Science of Sintering, 50(3), 291-298.

32. Suwarnkar M.B., Dhabbe R.S., Kadam A.N., Garadkar K.M. 2014. Enhanced photocatalytic activity of Ag doped $\mathrm{TiO}_{2}$ nanoparticles synthesized by a microwave assisted method. Ceramics International, 40(4), 5489-5496.

33. Valencia S., Marín J.M., Restrepo G. 2009. Study of the bandgap of synthesized titanium dioxide nanoparticles using the sol-gel method and hydrothermal treatment. The Open Materials Science Journal, 4(1).

34. Wang G. 2007. Hydrothermal synthesis and photocatalytic activity of nanocrystalline $\mathrm{TiO}_{2}$ powders in ethanol-water mixed solutions. Journal of Molecular Catalysis A: Chemical, 274(1-2), 185-191.

35. Yu J., Wang G., Cheng B., Zhou M. 2007. Effects of hydrothermal temperature and time on the photocatalytic activity and microstructures of bimodal mesoporous $\mathrm{TiO}_{2}$ powders. Applied Catalysis B. Environmental, 69(3-4), 171-180.

36. Zait Y., Konsens I., Schwartz A. 2020. Elucidating the limiting factors for regeneration and successful establishment of the thermophilic tree Ziziphus Spina-Christi under a changing climate. Scientific Reports, 10(1), 1-2.

37. Zhao L., Han M., Lian J. 2008. Photocatalytic activity of $\mathrm{TiO}_{2}$ films with mixed anatase and rutile structures prepared by pulsed laser deposition. Thin Solid Films, 516(10), 3394-3398. 